\title{
Antiangiogenic tyrosine kinase inhibition related gastrointestinal perforations: a case report and literature review
}

\author{
Maudy Walraven - Petronella O. Witteveen • \\ Martijn P. J. Lolkema $\cdot$ R. van Hillegersberg • \\ Emile E. Voest $\cdot$ H. M. W. Verheul
}

Received: 22 September 2010/Accepted: 14 December 2010/Published online: 29 December 2010

(C) The Author(s) 2010. This article is published with open access at Springerlink.com

\begin{abstract}
Anti-VEGF (vascular endothelial growth factor) therapy with the monoclonal antibody bevacizumab can cause gastrointestinal (GI) perforations. In recent years it became apparent that GI perforations also occur during treatment with antiangiogenic tyrosine kinase inhibitors (TKIs). It is of clinical importance to consider (vague) abdominal complaints during antiangiogenic treatment as a sign of a GI perforation. To illustrate this serious complication, we report four cases of antiangiogenic treatment related GI perforations. In three cases this was due to antiangiogenic TKI treatment. Reported risk factors of GI perforations due to bevacizumab include the presence of a primary tumor in situ and recent history of endoscopy or abdominal radiotherapy. Pathology assessments of surgical removal of the perforated intestinal part reveal that perforations are predominantly seen at the tumor or anastomotic site, in case of carcinomatosis or diverticulitis or when GI obstruction or an intra-abdominal abcess is present. Whether the same risk factors may be involved in antiangiogenic TKI related GI perforations is unknown. The underlying mechanisms responsible for GI perforation during antiangiogenic treatment is unknown, but disturbance of host cell homeostasis of immune cells as well as platelet-endothelial
\end{abstract}

M. Walraven · H. M. W. Verheul ( $\square)$

Department of Medical Oncology, VU University Medical

Center, De Boelelaan 1117, 1081 HV Amsterdam,

The Netherlands

e-mail: h.verheul@vumc.nl

M. Walraven · P. O. Witteveen - M. P. J. Lolkema · E. E. Voest Department of Medical Oncology, University Medical Center Utrecht, Utrecht, The Netherlands

R. van Hillegersberg

Department of Surgery, University Medical Center Utrecht, Utrecht, The Netherlands cell interactions may play an important role. In conclusion, while clinical awareness that antiangiogenic treatment can cause GI perforations is critical for current medical practice, it is also very important to get more insight in its underlying mechanisms so that this life-threatening complication may be prevented in the near future.

Keywords GI perforation - TKI - Risk factors · Biological mechanisms

\section{Introduction}

Malignant tumors depend on the formation of new blood vessels from the pre-existing vasculature for their growth and dissemination [1]. This process, called angiogenesis, is regulated by pro- and antiangiogenic factors. One of the main angiogenic factors is vascular endothelial growth factor (VEGF), which exerts its function by activation of VEGF tyrosine kinase receptors [2]. Multiple agents that target these angiogenic growth factor signaling pathways have been developed. Since these agents only interfere with growth factor signaling pathways in proliferating endothelial cells, serious toxicities from these agents were not expected. Normally, more than $99 \%$ of the endothelial cells are quiescent in the absence of malignancy and angiogenesis only occurs during wound healing or in the menstrual cycle [3]. However, in contrast to preclinical tumor models, incidental severe toxicities were observed during clinical development of these agents. For example, incidences of 1.5-5.4\% were reported on GI perforations induced by treatment with the humanized monoclonal VEGF-antibody bevacizumab $[4,5]$. Only a few cases of GI perforations have been reported for antiangiogenic tyrosine kinase inhibitors (TKIs) such as sunitinib or sorafenib. 
In this report we present four cases of antiangiogenic treatment related GI perforations, of which in three cases an antiangiogenic TKI was responsible for this complication. In addition, we discuss current views on the potential risk factors and mechanisms of antiangiogenic treatment related GI perforations.

\section{Case reports}

\section{Bevacizumab}

A 74-year-old man with a medical history of right hemicolectomy and hepatectomy for metastasized colon carcinoma was treated in adjuvant setting with oxaliplatin, capecitabine and bevacizumab. Because of rectal blood loss during the second chemotherapy cycle, a colonoscopy with subsequent band ligation of observed hemorrhoids was performed. Three weeks later, the patient was admitted to the hospital with persistent diarrhea, severe anal pain and malaise. Body temperature and blood pressure were normal, but pulse frequency was increased (105 bpm). Anal examination was very painful, but no abnormalities were palpable. Laboratory and faeces examination as well as abdominal and chest X-rays revealed no abnormalities. At colonoscopy multiple deep colonic and perianal ulcers were found and considered as drug induced enterocolitis (Fig. 1). Therefore capecitabine treatment was immediately terminated. Despite this treatment interruption, the patient got worse and subsequently a laparotomy was performed. At the site of the previously placed band ligations ( 3 weeks before), peri-anal and -rectal necrotic cavities connected to the anal canal were found. The patient recovered within a few weeks after extended necrotectomies, a Hartmann-procedure and antibiotic treatment. No further adjuvant chemotherapy was administered.

\section{Sorafenib}

A 68-year-old man with a medical history of metastasized renal cell carcinoma (RCC) started treatment with sorafenib, after previous nephrectomy and immunotherapy (interferon-alpha), upon disease progression. Sorafenib treatment resulted in a rapid partial response. However, the patient developed fever and abdominal pain 5 months after start of sorafenib treatment and his condition deteriorated within hours. The patient suffered from diarrhea and substantial rectal bleeding. Physical examination revealed fever, abdominal pain and hepatomegaly. Laboratory results showed anemia and signs of inflammation (hemoglobin $11.8 \mathrm{~g} / \mathrm{dl}$ (normal value between 13.5 and16.5 g/dl), C-reactive protein (CRP) $57 \mathrm{mg} / \mathrm{l}$ (normal value between 0 and $10 \mathrm{mg} / \mathrm{l}$ ) and Leukocyte counts $9.5 \times 10^{9} / 1$ (normal
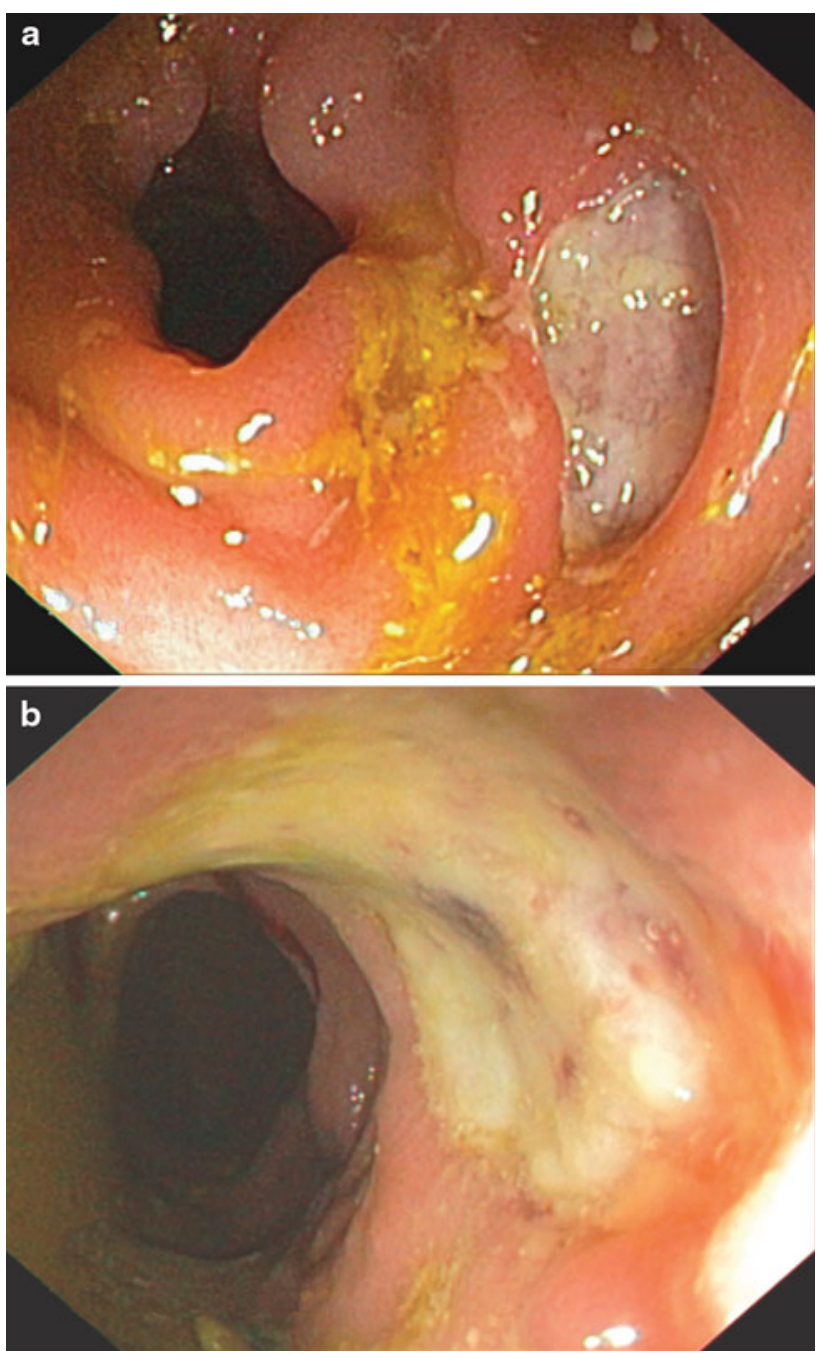

Fig. 1 Endoscopy results of patient 1 visualizing deep colonic ulcers

value between 4.0 and $\left.10 \times 10^{9} / 1\right)$. Computed tomography (CT), performed because of progressive diarrhea together with substantial rectal bleeding with a decrease in hemoglobin to $8.5 \mathrm{~g} / \mathrm{dl}$, revealed colonic perforation into the necrotic liver metastasis (Fig. 2). Based on these findings, sorafenib treatment was terminated and antibiotics were prescribed. Because a surgical resection of these necrotic liver metastases was impossible, a terminal ileostomy with a slime fistula was constructed. Within a few days the patient recovered rapidly and could be discharged from the hospital. Two months later, when the patient was fully recovered from this episode, an mTOR inhibitor was prescribed because of disease progression.

\section{Bevacizumab plus an antiangiogenic TKI}

After optimal interval debulking and extensive treatment with standard chemotherapy, a 67-year-old woman with advanced ovarian cancer and extended peritonitis 

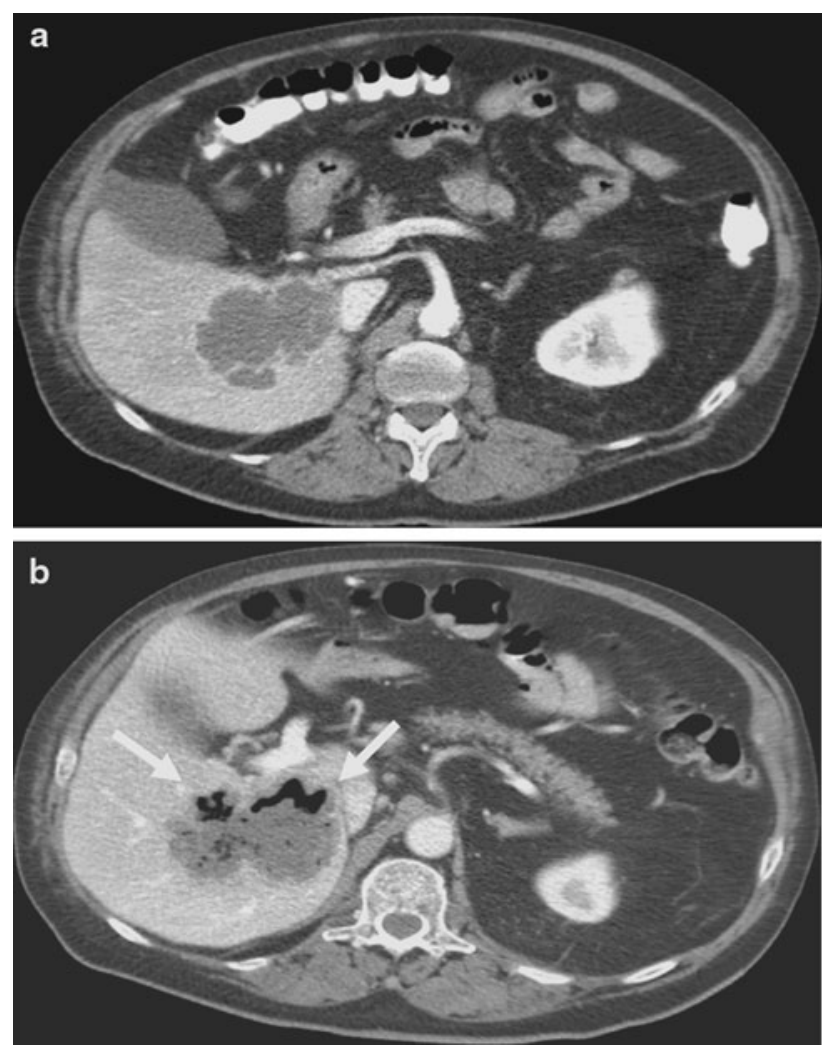

Fig. 2 Abdominal CT-scan of patient 2, performed pre-treatment (a) and post treatment (b), revealing colonic perforation into the necrotic liver metastasis (arrows) post-treatment

carcinomatosa participated upon progression in a phase I trial with bevacizumab combined with an experimental antiangiogenic TKI. Targets of this TKI include VEGFR-2 and PDGFR. One month after start of treatment she was admitted to the hospital because of progressive pain in groin and lower left abdominal part accompanied by fever and elevated inflammation parameters (CRP $290 \mathrm{mg} / \mathrm{l}$, Leukocyte counts $\left.13.8 \times 10^{9} / \mathrm{l}\right)$. A CT-scan revealed a necrotic tumor mass in the pelvis with, secondary to the tumor response, retroperitoneal perforation. Surgical resection of this retroperitoneal complication was not feasible and optimal palliative care was initiated.

\section{Sunitinib}

A 62-year-old woman with a medical history of metastasized RCC, for which she underwent surgery and radiotherapy, started sunitinib upon disease progression. During the second 6 week treatment cycle, she developed pain at lower back and bottom accompanied by fever. At physical examination, a peri-anal fistula was found and laboratory results supported systemic inflammation (CRP $>500 \mathrm{mg} / \mathrm{l})$. Magnetic Resonance Imaging revealed widespread perianal abscesses and fistulas. As extensive surgical resection was no reasonable option, optimal palliative care was provided.

\section{Discussion}

The incidence of sunitinib or sorafenib related GI perforation is unknown, since only few cases were reported in trials [6-13] and case reports [14-20]. Because of the potential serious outcome, it would be extremely helpful if we could predict patients at-risk on basis of risk factors and underlying biological mechanisms. In addition, more insight in these underlying mechanisms is important to develop potential novel agents with an improved toxicity profile.

Since the first observations of GI perforation during bevacizumab treatment, the risk factors of primary tumor in situ and recent history of endoscopy or abdominal radiotherapy [5, 21-26] were described. Pathological findings, frequently associated with observed perforations, include perforation at the tumor or anastomotic site, abdominal carcinomatosis, diverticulitis, GI obstruction and intra-abdominal abcess [5, 22-24]. Different biological mechanisms of bevacizumab related perforations have been theorized, which we have outlined in the next part. Whether the same risk factors and mechanisms may be involved in TKI related perforation is unknown, but seems very likely, because both type of agents inhibit VEGF signaling. We have summarized in Table 1 that for both type of agents, gastrointestinal perforations were reported in diverse parts of the gastrointestinal tract. In the reported cases for sunitinib and sorafenib, tumor cells at the site of perforation and previous radiation treatment were frequently mentioned similar to bevacizumab reports [6, 13-17].

Possible mechanisms of GI perforations due to angiogenesis inhibition

Tol et al. [27] suggested a relationship between bevacizumab treatment and ulcer development, which may eventually cause a GI perforation. In a phase III study with 755 patients receiving chemotherapy with bevacizumab plus or minus cetuximab, twelve GI perforations were observed of which four were located in an ulcer. The high incidence of ulcers in this study ( 1.3 vs. $0.1 \%$ in the general population), the occurrence of perforations early in treatment, the established role of VEGF in ulcer healing [28-30] and the inhibitory effect of bevacizumab on wound healing support their hypothesis. Since the majority of perforations were located at the primary tumor site, preexistent mucosal lesions were expected as preferential localizations. 
Table 1 An overview of the percentages and localisations of all reported gastrointestinal perforations for treatment with sunitinib and sorafenib and of a few larger studies and meta-analyses regarding bevacizumab treatment

\begin{tabular}{|c|c|c|c|c|c|}
\hline $\begin{array}{l}\text { Antiangiogenic } \\
\text { agent }\end{array}$ & Type of study/article & Tumor type & $\begin{array}{l}\text { Percentage } \\
\text { (amount) }\end{array}$ & Localisation & Article \\
\hline \multirow[t]{8}{*}{ Sunitinib } & Phase I & Various & $7.1 \%(2 / 28)$ & Rectum (fistula) & Faivre et al. [6] \\
\hline & Phase II & $\mathrm{RCC}$ & $1.1 \%(1 / 88)$ & Colon & De Mulder et al. [7] \\
\hline & Phase II & PAC & $2 \%$ & Gastrointestinal & O'Reilly et al. [8] \\
\hline & Case report & GIST & $1 \mathrm{pt}$ & Transverse colon & Hur et al. [16] \\
\hline & Retrospective & GIST & $7.1 \%(3 / 42)$ & Bowel & Ruka et al. [17] \\
\hline & $\begin{array}{l}\text { Retrospective (sunitinib } \\
\text { or imatinib) }\end{array}$ & GIST & 4 pts & Intestinal & Raut et al. [18] \\
\hline & Case report & $\mathrm{RCC}$ & $2 \mathrm{pts}$ & Ascending colon & Flaig et al. [19] \\
\hline & Case report & $\mathrm{RCC}$ & $1 \mathrm{pt}$ & Peri-anal (fistulas) & Walraven et al. \\
\hline \multirow[t]{9}{*}{ Sorafenib } & Phase II & Sarcomas & $0.7 \%(1 / 144)$ & Bowel & Maki et al. [9] \\
\hline & Phase II & Melanoma & $2.7 \%(1 / 37)$ & Intestinal & Min et al. [10] \\
\hline & Phase II & GIST & $3.8 \%(1 / 26)$ & Not mentioned & Wiebe et al. [11] \\
\hline & Phase II & $\begin{array}{l}\text { Galbladder canc./ } \\
\text { cholangiocarc. }\end{array}$ & $2.7 \%(1 / 36)$ & Gastrointestinal & El-Khoueiry et al. [12] \\
\hline & Phase I (plus chemo) & NSCLC & $7.7 \%(1 / 13)$ & Small bowel & Okamoto et al. [13] \\
\hline & Case report & $\mathrm{RCC}$ & $1 \mathrm{pt}$ & Left colon & Eng et al. [14] \\
\hline & Case report & $\mathrm{RCC}$ & $1 \mathrm{pt}$ & $\begin{array}{l}\text { Transv. and sigm. colon } \\
\text { (multiple perforations) }\end{array}$ & Peters et al. [15] \\
\hline & Case report & Melanoma & $1 \mathrm{pt}$ & $\begin{array}{l}\text { Ascending colon } \\
\text { (multiple perforations) }\end{array}$ & Frieling et al. [20] \\
\hline & Case report & $\mathrm{RCC}$ & $1 \mathrm{pt}$ & Colon & Walraven et al. \\
\hline \multirow[t]{8}{*}{ Bevacizumab } & Phase III (plus chemo) & $\mathrm{CRC}$ & $1.5 \%(6 / 393)$ & Gastrointestinal & Hurwitz et al. [5] \\
\hline & Phase III (plus chemo) & CRC & $1.9 \%(37 / 1914)$ & Gastrointestinal & Van Cutsem et al. [21] \\
\hline & $\begin{array}{l}\text { BRITE registry (plus } \\
\text { chemo) }\end{array}$ & $\mathrm{CRC}$ & $1.7 \%(34 / 1968)$ & Gastrointestinal & Sugrue et al. [23] \\
\hline & $\begin{array}{l}\text { Literat. search (single } \\
\text { agent/plus chemo/plus } \\
\text { erlotinib) }\end{array}$ & $\begin{array}{l}\text { Gynaecologic } \\
\text { tumors }\end{array}$ & $5.4 \%(16 / 298)$ & Bowel & Han et al. [4] \\
\hline & $\begin{array}{l}\text { Retrospective (single } \\
\text { agent/plus chemo) }\end{array}$ & Various & $1.7 \%(24 / 1442)$ & $\begin{array}{l}\text { Gastroesophageal, -jejunostomy, } \\
\text { duodeno-pancreatic, small } \\
\text { bowel, appendix, colorectal }\end{array}$ & Badgwell et al. [24] \\
\hline & $\begin{array}{l}\text { Meta-analysis (plus } \\
\text { IFN/chemotherapy/ } \\
\text { erlotinib) }\end{array}$ & Various & $\begin{array}{l}0.9 \% \text { (of }>6000 \\
\text { pts) }\end{array}$ & Gastrointestinal & Hapani et al. [42] \\
\hline & $\begin{array}{l}\text { Case report (plus } \\
\text { chemo) }\end{array}$ & $\mathrm{CRC}$ & $1 \mathrm{pt}$ & Rectal and anal & Walraven et al. \\
\hline & $\begin{array}{l}\text { Case report (plus } \\
\text { antiangiogenic TKI) }\end{array}$ & Ovarian cancer & $1 \mathrm{pt}$ & Colon & Walraven et al. \\
\hline
\end{tabular}

$R C C$ renal cell carcinoma, PAC pancreas adenocarcinoma, GIST gastrointestinal stromal tumor, NSCLC non-small cell lung cancer, $C R C$ colorectal cancer

In another report it was speculated that bevacizumab induced VEGF inhibition might result in the cholesterol emboli syndrome (CES), which may consequently give rise to GI perforations due to mesenteric ischemia [31]. Hypertension in combination with eosinophilia is a feature of CES. All three out of twenty-two prospectively observed patients who developed hypertension during bevacizumab treatment had atherosclerotic risk factors, an increased heart rate and eosinophilia at onset of hypertension. In this report it was hypothesized that CES might cause all acute bevacizumab related complications in atherosclerotic patients, including GI perforations as a consequence of mesenteric ischemia.

Alternatively, Saif et al. [22] postulated that GI perforation is caused directly by regression of normal blood vessels in the GI tract, induced by excessive VEGF inhibition. The authors extrapolated data from animal models in which VEGF inhibition has shown to reduce vascular density in the small intestinal villi as well as in other organs [32]. 
In a recent editorial on the risk of bevacizumab associated GI perforation in ovarian cancer it was speculated that bevacizumab induces necrosis of malignant ovarian cells that invade the bowel serosa resulting in GI perforation [4]. In addition, in this editorial it was suggested that increased pressure due to abdominal carcinomatosis or adhesions from prior surgeries might lead to micro-perforations in vulnerable areas of the bowel, with subsequent delayed healing due to bevacizumab. Finally, loss of nitric oxide (NO) release due to VEGF inhibition, leading to decreased blood flow to the splanchnic vasculature, was proposed to result in bowel infarction and perforation at areas with marginal blood supply.

On account of early closure of the ORBIT trial, evaluating bevacizumab treatment in platinum resistant ovarian cancer, tumor involvement of the bowel was suggested [33]. Five out of 44 patients developed GI perforation and showed radiographic evidence of bowel involvement at study entry. A significant association of GI perforations with increased number of prior chemotherapy regimens (respectively three) and a non-significant relation with bowel wall thickening/obstruction were found. In contrast, in another study with twenty-five heavily pretreated (median of five prior chemotherapy regimens) patients with advanced ovarian cancer, treatment with bevacizumab did not cause any GI perforations [34].

We recently discussed the role of platelets in antiangiogenic treatment related toxicity $[35,36]$. Platelets contain VEGF in their $\alpha$-granules which they secrete upon activation and on the other hand VEGF activation of the endothelium results in platelet binding and subsequent activation [37-39]. In addition, we found that bevacizumab is taken up by platelets, leading to VEGF neutralization [35]. Since VEGF is an endothelial cell survival factor $[2,40,41]$, we postulated that the subsequent disturbed platelet-endothelial cell interaction might be involved in GI perforation, disturbed wound healing and bleeding complications [36]. The platelet-endothelial cell homeostasis may be disturbed by antiangiogenic treatment. Therefore an increased leakiness and extravasation of inflammatory cells may cause submucosal inflammation and subsequent ulcer formation.

It is of clinical importance to study underlying biological mechanisms of bevacizumab related GI perforation. In addition, it is expected that these underlying mechanisms and risk factors might account for antiangiogenic TKI treatment as well. Risk factors of tumors at the primary site and recent history of endoscopy or abdominal radiotherapy should be taken into account before treatment initiation with angiogenesis inhibitors. In ovarian cancer patients it is recommended to consider the number of prior chemotherapy regimens and abdominal surgeries and to exclude tumor involvement of the bowel by physical examination and CT-scan upon start of treatment with angiogenesis inhibitors. Endoscopic evaluation is advised in patients with symptoms possibly related to GI ulcer during treatment [27]. In addition, based on this report, rubber band ligation should be prevented until bevacizumab or TKI treatment is interrupted or terminated. The third case of GI perforation during combined bevacizumab and TKI treatment emphasizes a possible increased perforation risk related to combination treatment with antiangiogenic agents with different biological mechanisms. Although most of the current preclinical and clinical knowledge on potential underlying mechanisms of angiogenesis inhibitor induced gastrointestinal perforations is on bevacizumab, based on preclinical and clinical studies potential underlying mechanisms as described may hold true for TKIinduced perforations as well.

In conclusion, we would like to advocate to include GI perforation in the differential diagnoses, when patients complain of (vague) abdominal pain during treatment with TKIs as well as with bevacizumab.

Acknowledgments Maudy Walraven was supported by by the Dutch Cancer Foundation and an AEGON scholarship.

Conflict of interest The authors declare that they have no conflict of interest.

Open Access This article is distributed under the terms of the Creative Commons Attribution Noncommercial License which permits any noncommercial use, distribution, and reproduction in any medium, provided the original author(s) and source are credited.

\section{References}

1. Folkman J (1990) What is the evidence that tumors are angiogenesis dependent? J Natl Cancer Inst 82(1):4-6

2. Ferrara N (2004) Vascular endothelial growth factor: basic science and clinical progress. Endocr Rev 25(4):581-611

3. Folkman J (2003) Fundamental concepts of the angiogenic process. Curr Mol Med 3(7):643-651

4. Han ES, Monk BJ (2007) What is the risk of bowel perforation associated with bevacizumab therapy in ovarian cancer? Gynecol Oncol 105(1):3-6

5. Hurwitz H, Fehrenbacher L, Novotny W, Cartwright T, Hainsworth J, Heim W, Berlin J, Baron A, Griffing S, Holmgren E, Ferrara N, Fyfe G, Rogers B, Ross R, Kabbinavar F (2004) Bevacizumab plus irinotecan, fluorouracil, and leucovorin for metastatic colorectal cancer. New Engl J Med 350(23):2335-2342

6. Faivre S, Delbaldo C, Vera K, Robert C, Lozahic S, Lassau N, Bello C, Deprimo S, Brega N, Massimini G, Armand JP, Scigalla P, Raymond E (2006) Safety, pharmacokinetic, and antitumor activity of SU11248, a novel oral multitarget tyrosine kinase inhibitor, in patients with cancer. J Clin Oncol 24(1):25-35

7. De Mulder PH, Roigas J, Gillessen S, Srinivas S, Pisa P, Vogelzang N, Fountzilas G, Peschel C, Baum C, Escudier B (2006) A phase II study of sunitinib administered in a continuous daily regimen in patients with cytokine-refractory metastatic renal cell carcinoma (mRCC). J Clin Oncol 24(1), 18S(June 20 Suppl):abstr 4529 
8. O'Reilly EM, Niedzwiecki D, Hollis DR, Bekaii-Saab TS, Pluard T, Duffy A, Overcash F, Ivy SP, Goldberg RM (2008) A phase II trial of sunitinib (S) in previously-treated pancreas adenocarcinoma (PAC), CALGB 80603. J Clin Oncol 26 (May 20 Suppl):abstr 4515

9. Maki RG, D’Adamo DR, Keohan ML, Saulle M, Schuetze SM, Undevia SD, Livingston MB, Cooney MM, Hensley ML, Mita MM, Takimoto CH, Kraft AS, Elias AD, Brockstein B, Blachere NE, Edgar MA, Schwartz LH, Qin LX, Antonescu CR, Schwartz GK (2009) Phase II study of sorafenib in patients with metastatic or recurrent sarcomas. J Clin Oncol 27(19):3133-3140

10. Min CJ, Liebes LF, Escalon J, Hamilton A, Yee H, Buckley MT, Wright JJ, Osman I, Polsky D, Pavlick AC (2008) Phase II trial of sorafenib (S [BAY 43-9006]) in metastatic melanoma (MM) including detection of BRAF with mutant specific-PCR (MSPCR) and altered proliferation pathways-final outcome analysis. J Clin Oncol 26 (May 20 Suppl):abstr 9072

11. Wiebe L, Kasza KE, Maki RG, D'Adamo DR, Chow WA, Wade JL, Agamah E, Stadler WM, Vokes EE, Kindler HL (2008) Activity of sorafenib (SOR) in patients (pts) with imatinib (IM) and sunitinib (SU)-resistant (RES) gastrointestinal stromal tumors (GIST): A phase II trial of the University of Chicago Phase II Consortium. J Clin Oncol 26(May 20 Suppl): abstr 10502

12. El-Khoueiry AB, Rankin C, Lenz HJ, Philip P, Rivkin SE, Blanke CD (2007) SWOG 0514: a phase II study of sorafenib (BAY 439006) as single agent in patients (pts) with unresectable or metastatic gallbladder cancer or cholangiocarcinomas. J Clin Oncol 25(1),18S(June 20 Suppl):abstr 4639

13. Okamoto I, Miyazaki M, Morinaga R, Kaneda H, Ueda S, Hasegawa Y, Satoh T, Kawada A, Fukuoka M, Fukino K, Tanigawa T, Nakagawa K (2009) Phase I clinical and pharmacokinetic study of sorafenib in combination with carboplatin and paclitaxel in patients with advanced non-small cell lung cancer. Investig New Drugs

14. Eng FC, Easson AM, Szentgyorgyi E, Knox JJ (2009) Sorafenib and surgical complications: a case report of adverse reaction to sorafenib during treatment for renal cell carcinoma. Eur J Surg Oncol 35(2):219-221

15. Peters NA, Richel DJ, Verhoeff JJ, Stalpers LJ (2008) Bowel perforation after radiotherapy in a patient receiving sorafenib. J Clin Oncol 26(14):2405-2406

16. Hur H, Park AR, Jee SB, Jung SE, Kim W, Jeon HM (2008) Perforation of the colon by invading recurrent gastrointestinal stromal tumors during sunitinib treatment. World J Gastroenterol 14(39):6096-6099

17. Ruka W, Rutkowski P, Nowecki Z, Dziewirski W (2009) Emergency surgery due to complications during molecular targeted therapy in advanced gastrointestinal stromal tumors (GIST). Ann Surg Oncol 15(Suppl 2):27(abstr 82)

18. Raut CP, Posner M, Desai J, Morgan JA, George S, Zahrieh D, Fletcher CD, Demetri GD, Bertagnolli MM (2006) Surgical management of advanced gastrointestinal stromal tumors after treatment with targeted systemic therapy using kinase inhibitors. J Clin Oncol 24(15):2325-2331

19. Flaig TW, Kim FJ, La Rosa FG, Breaker K, Schoen J, Russ PD (2009) Colonic pneumatosis and intestinal perforations with sunitinib treatment for renal cell carcinoma. Investig New Drugs 27(1):83-87

20. Frieling T, Heise J, Wassilew SW (2009) Multiple colon ulcerations, perforation and death during treatment of malignant melanoma with sorafenib. Deutsche medizinische Wochenschrift (1946) 134(28-29):e1-e2, 1464-1466

21. Van Cutsem E, Rivera F, Berry S, Kretzschmar A, Michael M, DiBartolomeo M, Mazier MA, Canon JL, Georgoulias V, Peeters M, Bridgewater J, Cunningham D (2009) Safety and efficacy of first-line bevacizumab with FOLFOX, XELOX, FOLFIRI and fluoropyrimidines in metastatic colorectal cancer: The BEAT study. Ann Oncol 20(11):1842-1847

22. Saif MW, Elfiky A, Salem RR (2007) Gastrointestinal perforation due to bevacizumab in colorectal cancer. Ann Surg Oncol 14(6):1860-1869

23. Sugrue M, Kozloff M, Hainsworth J, Badarinath S, Cohn A, Flynn P, Steis R, Dong W, Sarkar S, Grothey A (2006) Risk factors for gastrointestinal perforations in patients with metastatic colorectal cancer receiving bevacizumab plus chemotherapy. J Clin Oncol 24(1), 18S (June 20 Suppl):abstr 3535

24. Badgwell BD, Camp ER, Feig B, Wolff RA, Eng C, Ellis LM, Cormier JN (2008) Management of bevacizumab-associated bowel perforation: a case series and review of the literature. Ann Oncol 19(3):577-582

25. Kabbinavar FF, Schulz J, McCleod M, Patel T, Hamm JT, Hecht JR, Mass R, Perrou B, Nelson B, Novotny WF (2005) Addition of bevacizumab to bolus fluorouracil and leucovorin in first-line metastatic colorectal cancer: results of a randomized phase II trial. J Clin Oncol 23(16):3697-3705

26. Parikh AA, Ellis LM (2008) Targeted therapies and surgical issues in gastrointestinal cancers. Targ Oncol 3:119-125

27. Tol J, Cats A, Mol L, Koopman M, Bos MM, van der Hoeven JJ, Antonini NF, van Krieken JH, Punt CJ (2008) Gastrointestinal ulceration as a possible side effect of bevacizumab which may herald perforation. Investig New Drugs 26(4):393-397

28. Yoshida M, Wakabayashi G, Ishikawa H, Kameyama K, Shimazu M, Tanabe M, Kawachi S, Kumai K, Kubota T, Otani Y, Saikawa Y, Sano K, Kitajima M (2003) A possible defensive mechanism in the basal region of gastric mucosa and the healing of erosions. Clin Hemorheol Microcirc 29(3-4):301-312

29. Tarnawski AS (2005) Cellular and molecular mechanisms of gastrointestinal ulcer healing. Dig Dis Sci 50(Suppl 1):S24-S33

30. Malara B, Josko J, Tyrpien M, Malara P, Steplewska K (2005) Dynamics of changes in vascular endothelial growth factor (VEGF) expression and angiogenesis in stress-induced gastric ulceration in rats. J Physiol Pharmacol 56(2):259-271

31. Mir O, Mouthon L, Alexandre J, Mallion JM, Deray G, Guillevin L, Goldwasser F (2007) Bevacizumab-induced cardiovascular events: a consequence of cholesterol emboli syndrome? J Natl Cancer Inst 99(1):85-86

32. Kamba T, Tam BY, Hashizume H, Haskell A, Sennino B, Mancuso MR, Norberg SM, O’Brien SM, Davis RB, Gowen LC, Anderson KD, Thurston G, Joho S, Springer ML, Kuo CJ, McDonald DM (2006) VEGF-dependent plasticity of fenestrated capillaries in the normal adult microvasculature. Am J Physiol 290(2):H560-H576

33. Cannistra SA, Matulonis UA, Penson RT, Hambleton J, Dupont J, Mackey H, Douglas J, Burger RA, Armstrong D, Wenham R, McGuire W (2007) Phase II study of bevacizumab in patients with platinum-resistant ovarian cancer or peritoneal serous cancer. J Clin Oncol 25(33):5180-5186

34. Simpkins F, Belinson JL, Rose PG (2007) Avoiding bevacizumab related gastrointestinal toxicity for recurrent ovarian cancer by careful patient screening. Gynecol Oncol 107(1):118-123

35. Verheul HM, Lolkema MP, Qian DZ, Hilkes YH, Liapi E, Akkerman JW, Pili R, Voest EE (2007) Platelets take up the monoclonal antibody bevacizumab. Clin Cancer Res 13(18 Pt 1):5341-5347

36. Verheul HM, Pinedo HM (2007) Possible molecular mechanisms involved in the toxicity of angiogenesis inhibition. Nat Rev 7(6):475-485

37. Wartiovaara U, Salven P, Mikkola H, Lassila R, Kaukonen J, Joukov V, Orpana A, Ristimaki A, Heikinheimo M, Joensuu H, Alitalo K, Palotie A (1998) Peripheral blood platelets express VEGF-C and VEGF which are released during platelet activation. Thromb Haemost 80(1):171-175 
38. Selheim F, Holmsen H, Vassbotn FS (2002) Identification of functional VEGF receptors on human platelets. FEBS Lett 512(1-3):107-110

39. Mohle R, Green D, Moore MA, Nachman RL, Rafii S (1997) Constitutive production and thrombin-induced release of vascular endothelial growth factor by human megakaryocytes and platelets. Proc Natl Acad Sci USA 94(2):663-668

40. Verheul HM, Hoekman K, Luykx-de Bakker S, Eekman CA, Folman CC, Broxterman HJ, Pinedo HM (1997) Platelet: transporter of vascular endothelial growth factor. Clin Cancer Res 3(12 Pt 1):2187-2190
41. Okuda Y, Tsurumaru K, Suzuki S, Miyauchi T, Asano M, Hong Y, Sone H, Fujita R, Mizutani M, Kawakami Y, Nakajima T, Soma M, Matsuo K, Suzuki H, Yamashita K (1998) Hypoxia and endothelin-1 induce VEGF production in human vascular smooth muscle cells. Life Sci 63(6):477-484

42. Hapani S, Chu D, Wu S (2009) Risk of gastrointestinal perforation in patients with cancer treated with bevacizumab: a metaanalysis. Lancet Oncol 10(6):559-568 